\title{
EFEITO DO USO DE CULTURA ADJUNTA (Lactobacillus helveticus) NA PROTEÓlISE, PROPRIEDADES VISCOELÁSTICAS E ACEITAÇÃo SENSORIAL DE QUEIJO PRATO LIGHT
}

\author{
Christiane Maciel V. BARROS ${ }^{2}$, Clarissa Reschke da CUNHA², Darlila A. GALLINA², \\ Luiz Antonio VIOTTO ${ }^{2}$, Walkiria H. VIOTTO ${ }^{2, *}$
}

\begin{abstract}
RESUMO
A proteólise, as propriedades viscoelásticas e a aceitação sensorial de queijo prato light fabricado com e sem adição de cultura adjunta (CAD) foram avaliadas. Os queijos foram fabricados a partir de leite microfiltrado. Dois tratamentos foram testados em duplicata: o queijo controle foi fabricado apenas com cultura mesófila tradicional (acidificante e aromatizante), e o outro foi fabricado com adição de CAD (Lactobacillus helveticus), além da cultura tradicional. A composição dos queijos foi determinada no quinto dia após a fabricação. A proteólise e as propriedades reológicas foram avaliadas nos dias 5, 25 e 45 após a fabricação. Os parâmetros viscoelásticos foram obtidos a partir de testes de relaxação. As amostras foram avaliadas sensorialmente por meio de testes de aceitação. Não houve diferença significativa $(p>0,05)$ na composição dos queijos. Os índices de profundidade de proteólise foram significativamente $(\mathrm{p}<0,05)$ maiores ao final do tempo de maturação para o queijo fabricado com adição de CAD. As propriedades viscoelásticas dos queijos não foram influenciadas pelo uso de CAD ( $\mathrm{p}>0,05)$. Nos testes de aceitação sensorial, o queijo produzido com CAD obteve notas significativamente $(\mathrm{p}<0,05)$ mais altas para os atributos aroma, textura e impressão global. Em relação ao atributo intenção de compra, $70 \%$ dos consumidores, certamente ou provavelmente, comprariam o queijo com CAD, enquanto apenas $43,4 \%$ teriam a mesma atitude em relação ao queijo controle.
\end{abstract}

Palavras-chave: queijo, cultura adjunta, proteólise, produto light, reologia.

\section{SUMMARY}

EFFECT OF ADJUNCT CULTURE (Lactobacillus helveticus) ON PROTEOLYSIS, VISCOELASTIC PROPERTIES AND SENSORY ACCEPTANCE OF REDUCED FAT PRATO CHEESE. Proteolysis, viscoelastic properties and sensory acceptance of reduced fat Prato cheeses made with and without adjunt culture (AC) were evaluated. The cheeses were made from microfiltered milk. Two different treatments were replicated twice: control cheese was made only with traditional starter, while the other was made with the addition of both AC (Lactobacillus helveticus) and traditional starter. Cheese composition was determined after 5 days of manufacture. Proteolysis and rheological properties were evaluated after 5, 25 and 45 days. Viscoelastic parameters were obtained using relaxation tests. Cheese sensory properties were evaluated using acceptability tests. There was no statistical difference ( $p>0,05)$ in cheese composition. The proteolysis depth indexes were significantly higher $(\mathrm{p}<0.05)$ at the end of maturation for cheese made with AC. There was no statistical difference $(p>0.05)$ in viscoelastic parameters for cheeses made with and without AC. Sensory acceptability tests indicated significant difference $(\mathrm{p}<0.05)$ between samples for flavor, texture and global impression. Cheese made with AC was better graded than cheese made only with starter. Buying intention grades showed that $70 \%$ consumers would certainly or probably buy cheese made with $\mathrm{AC}$, while only $43.4 \%$ would behave the same with control cheese.

Keywords: cheese, adjunct culture, proteolysis, light food, rheology.

\section{1 - INTRODUÇÃO}

Queijos de baixo teor de gordura produzidos por métodos tradicionais costumam apresentar defeitos sensoriais, como aroma fraco, sabores indesejáveis e textura muito firme e elástica [1, 18, 22].

Existem diversas técnicas disponíveis para melhorar a textura de queijos de baixo teor de gordura, como o uso de substitutos de gordura, redução do tempo e temperatura de cozimento da massa, uso de leite homogeneizado, adição de concentrados protéicos do soro, inclusão de

\footnotetext{
${ }^{1}$ Recebido para publicação em 8/4/2004. Aceito para publicação em 23/1/2006 (001322)

${ }^{2}$ Faculdade de Engenharia de Alimentos. Universidade Estadual de Campinas (Unicamp)

Caixa Postal 6.121

CEP 13083-970 - Campinas (SP)

E-mail:walkiria@fea.unicamp.br

*A quem a correspondência deve ser enviada
}

proteínas do soro por ultrafiltração, entre outras [6, 14, 19]. No entanto, essas técnicas não promovem melhorias no sabor, não solucionando um dos principais problemas dos queijos de baixo teor de gordura.

Uma das alternativas para minimizar, ao mesmo tempo, os defeitos de sabor e de textura dos queijos de baixo teor de gordura, é a adição de culturas adjuntas [6, 19], que podem ser definidas como linhagens selecionadas de bactérias lácticas ou de outros microorganismos relacionados com a maturação do queijo, que são adicionadas juntamente com o fermento láctico, com o objetivo principal de melhorar a qualidade sensorial do produto. As culturas adjuntas podem melhorar ou acelerar o desenvolvimento do sabor dos queijos por meio do aumento da proteólise secundária. De modo geral, a adição de culturas adjuntas resulta em um aumento da atividade da aminopeptidase, que é responsável pela redução do sabor amargo e pelo aumento da concentração de peptídeos de sabor desejável e precursores de sabor [6, 7]. 
O Lactobacillus helveticus tem sido usado como cultura adjunta na produção de queijos semiduros de baixo teor de gordura, promovendo aumento dos níveis de proteólise, diminuição do sabor amargo e intensificação dos sabores desejáveis [6]. ARDO et al. [2] estudaram a qualidade dos queijos gouda com baixo teor de gordura contendo Lactobacillus helveticus CNRZ 303 como cultura adjunta e concluíram que o uso dessa cultura melhorou o sabor, diminuiu o sabor amargo e acelerou a proteólise desses queijos. JOHNSON \& ETZEL [16] obtiveram resultados semelhantes com a adição de Lactobacillus helveticus atenuado CNRZ 32 em queijo cheddar, com $33 \%$ de redução de gordura.

A diversidade da microflora é considerada o principal fator determinante do perfil de aroma e sabor dos queijos [18]. Assim, quando se estuda a influência de culturas adjuntas no sabor e aroma de queijos, é interessante partir de um leite estéril ou com uma contagem microbiológica inicial bastante baixa; dessa maneira, é possível avaliar com mais precisão o papel das culturas adjuntas, já que a competição com outros microorganismos é minimizada. A microfiltração é uma boa alternativa para obter leites com baixas contagens microbianas, já que permite remover entre 99,1 e 99,9\% das bactérias e esporos do leite [20], sem os inconvenientes do uso de altas temperaturas.

No caso do queijo prato, não apenas a textura, mas também o sabor, são atributos importantes na determinação da qualidade. Assim, a adição de culturas adjuntas pode ser interessante no sentido de melhorar a aceitação sensorial de queijos prato de baixo ou reduzido teor de gordura. O objetivo deste trabalho foi avaliar o efeito do uso de Lactobacillus helveticus como cultura adjunta na proteólise, nas propriedades viscoelásticas e na aceitação sensorial de queijo prato light.

\section{2 - MATERIAL E MÉTODOS}

\section{1 - Microfiltração do leite}

Leite desnatado pasteurizado proveniente de um laticínio da região de Campinas foi aquecido a $50^{\circ} \mathrm{C}$ e microfiltrado em sistema dotado de membrana cerâmica de 19 canais, composta de óxido de alumina, marca Exekia ${ }^{\circledR}$, com diâmetro médio de poro igual a $0,8 \mu \mathrm{m}$ e área superficial de $0,24 \mathrm{~m}^{2}$. As condições operacionais foram pressão transmembrana de $1,6 \mathrm{kgf} / \mathrm{cm}^{2}$ e velocidade de $6,2 \mathrm{~m} / \mathrm{s}$. O leite foi microfiltrado até a obtenção de um retentado com fator de concentração (FC) igual a 5. O fator de concentração (FC) foi calculado conforme a equação abaixo:

$$
\mathrm{FC}=\frac{\text { massa de leite }(\mathrm{kg})}{\text { massa de leite }(\mathrm{kg}) \text { - massa de permeado }(\mathrm{kg})}
$$

O permeado obtido a partir do processo de microfiltração foi utilizado na fabricação dos queijos.

\section{2 - Fabricação do queijo prato light}

Os queijos foram fabricados de acordo com o fluxograma da Figura 1. Para cada tratamento foram conduzidas duas repetições. O leite microfiltrado $(80 \mathrm{~L})$, com teor de gordura igual a $0,05 \%$, foi dividido em duas partes iguais e padronizado com creme de leite esterilizado comercial, para um teor final de gordura igual a $0,4 \%$. Cada parte foi submetida a um tipo de tratamento. O primeiro tratamento consistiu na fabricação de um queijo controle, usando cultura láctica tradicional (cultura mesófila acidificante e aromatizante Flora Dânica CHN-22 - Lactococcus lactis subsp. lactis, Lactococcus lactis subsp. cremoris, Lactoccocus lactis subsp. lactis biovar. diacetylactis, Leuconostoc mesenteroides subsp. cremoris). No segundo tratamento, o queijo foi fabricado adicionando-se uma cultura adjunta (Lactobacillus helveticus LBH-O2), além da cultura tradicional. Foram utilizadas culturas comerciais fornecidas pela Christian Hansen ${ }^{\circledR}$.

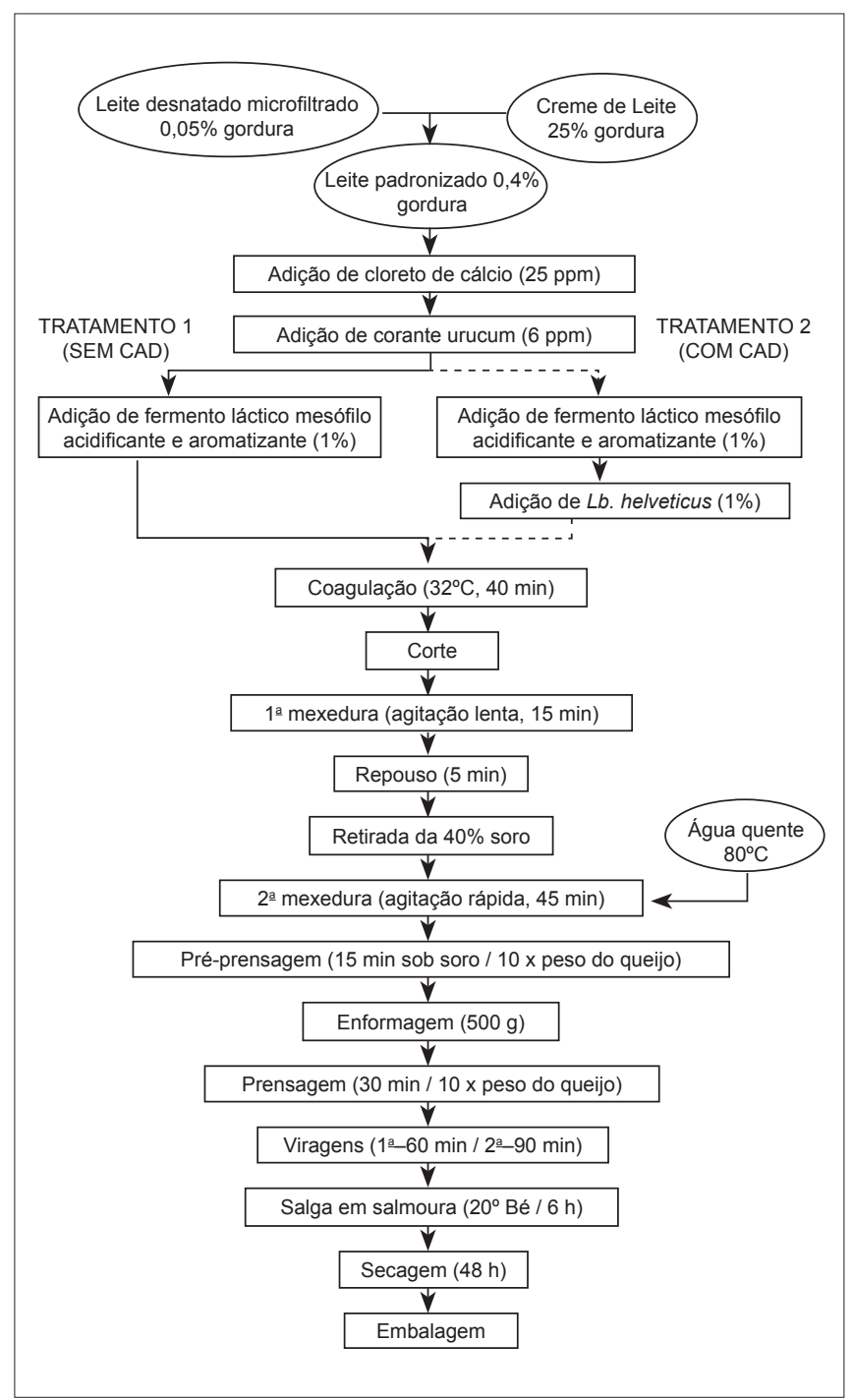

FIGURA 1 - Fluxograma de processamento do queijo prato 


\section{3 - Composição química}

O leite microfiltrado foi submetido a análises de: $\mathrm{pH}$, pelo método potenciométrico; densidade, pelo método do lactodensímetro; acidez titulável [3]; e gordura, utilizando-se o método de extração etérea de Mojonnier [3]. Os queijos foram submetidos, após 5 dias de fabricação, a análises de: $\mathrm{pH}$, pelo método potenciométrico; acidez titulável, segundo AOAC [3]; gordura, pelo método de Gerber [15]; umidade, pelo método gravimétrico, em estufa de circulação forçada, a $100^{\circ} \mathrm{C} / 24 \mathrm{~h}$ [3]; sal, pelo método de Volhard [21]; nitrogênio total, pelo método de Kjeldahl [3]; nitrogênio não protéico, pela determinação de nitrogênio total na fração solúvel em ácido tricloroacético (TCA) 12\% [3]; e nitrogênio não caséico, por meio da determinação de nitrogênio total na fração solúvel a pH 4,6 [5]. Os valores de nitrogênio foram multiplicados pelo fator 6,38 para a obtenção dos valores equivalentes de proteína. Todas as análises físico-químicas foram realizadas em triplicata.

\section{4 - Proteólise}

A proteólise dos queijos foi monitorada nos dias 5, 25 e 45 após a fabricação. Os índices de extensão e profundidade de proteólise foram determinados de acordo com as Equações 2 e 3, respectivamente:

Extensão $=\frac{(\% \text { nitrogênio solúvel a pH } 4,6) \times 100}{\% \text { nitrogênio total }}$

Profundidade $=\frac{(\% \text { nitrogênio solúvel em TCA } 12 \%) \times 100}{\% \text { nitrogênio total }}$

onde: TCA=ácido tricloroacético.

\section{5 - Análises reológicas dos queijos}

O comportamento reológico dos queijos foi avaliado após 5, 25 e 45 dias de armazenamento refrigerado, por meio de testes de relaxação. As análises foram realizadas em um texturômetro TA-XT2, da Texas Instruments, com uma célula de carga de $50 \mathrm{~kg}$. As amostras foram preparadas retirando-se cilindros de $20 \mathrm{~mm}$ de diâmetro por $24 \mathrm{~mm}$ de altura dos queijos, não sendo utilizados o centro e as bordas. Os cilindros foram embalados individualmente em sacos plásticos resistentes à penetração de líquidos e mantidos em banho de água gelada a $10^{\circ} \mathrm{C}$ por $1 \mathrm{~h}$ e $30 \mathrm{~min}$ antes do início dos testes. Durante os ensaios, as amostras foram comprimidas por uma placa de alumínio de $35 \mathrm{~mm}$ de diâmetro. Todas as determinações foram realizadas em seis replicatas.

Os testes de relaxação foram realizados medindo-se a queda da força durante 10 min após a deformação da amostra. A velocidade de compressão foi igual a $1 \mathrm{~mm} / \mathrm{s}$, e a deformação foi igual a $10 \%$ da altura inicial da amostra. Testes preliminares mostraram que, nessas condições, houve uma relação praticamente linear entre tensão e deformação durante o estágio inicial de compressão (ou seja, os ensaios foram realizados dentro do intervalo de viscoelasticidade linear).

A análise dos resultados foi feita conforme descrito por BERTOLA, BEVILACQUA \& ZARITSKY [4]. As curvas de relaxação foram expressas adimensionalmente usando a relação $\mathrm{F}(\mathrm{t}) / \mathrm{F}_{0}$ versus tempo, onde $\mathrm{F}(\mathrm{t})$ é a força instantânea durante o tempo de relaxação e $\mathrm{F}_{0}$ é a força inicial. As curvas assim obtidas foram ajustadas a um modelo viscoelástico com dois elementos de Maxwell e um elemento elástico em paralelo, representado pela Equação (4):

$$
F^{*}(t)=\frac{F(t)}{F_{0}}=S_{0}+S_{1} \cdot \exp \left(-t / \tau_{1}\right)+S_{2} \cdot \exp \left(-t / \tau_{2}\right)
$$

onde $\mathrm{S}_{0}, \mathrm{~S}_{1}$ e $\mathrm{S}_{2}$ são constantes que dependem das propriedades viscoelásticas do material e $\tau_{1}$ e $\tau_{2}$ são os tempos de relaxação.

Em termos do módulo de elasticidade, tem-se (Equação (5)):

$E(t)=E_{0}+E_{1} \cdot \exp \left(-t / \tau_{1}\right)+E_{2} \cdot \exp \left(-t / \tau_{2}\right)$

onde $\mathrm{E}_{1}$ e $\mathrm{E}_{2}$ são os módulos de elasticidade dos elementos 1 e 2 e $\mathrm{E}_{0}$ é o módulo de elasticidade de equilíbrio, ou o módulo de elasticidade a um tempo infinito. $\mathrm{E}_{0}, \mathrm{E}_{1}$ e $\mathrm{E}_{2}$ foram obtidos a partir dos coeficientes $\mathrm{S}_{0}, \mathrm{~S}_{1}$ e $\mathrm{S}_{2}$ de acordo com a Equação (6):

$E_{i}=\frac{S_{i} \cdot F_{0}}{\epsilon \cdot A_{0}}, i=1,2,0$

onde $\mathrm{A}_{0}$ é a área de compressão e $\epsilon=1-\left(\mathrm{H} / \mathrm{H}_{0}\right)$ é a deformação.

O valor da viscosidade do elemento i $\left(\eta_{i}\right)$ foi estimado pela Equação (7):

$\eta_{i}=E_{i} \cdot \tau_{i}, i=1,2$

\section{6 - Análise sensorial}

As amostras de queijo prato light desenvolvidas com e sem adição de CAD foram submetidas a um teste sensorial de aceitação e preferência utilizando um painel não treinado de 30 provadores. As amostras foram avaliadas após 40 dias de fabricação. Foram analisados os atributos aparência, aroma, sabor, textura e impressão global, além da intenção de compra do produto.

\section{7 - Planejamento experimental e análise estatística dos resultados}

O delineamento experimental foi do tipo aleatorizado em blocos. O fator estudado foi a adição de cultura adjunta, nos 
níveis com e sem CAD. Esses dois tratamentos foram realizados em duplicata, resultando em quatro experimentos. Os resultados da composição química dos queijos foram analisados por meio da Análise de Variância (ANOVA), utilizando-se o teste de Tukey para verificar diferenças entre as médias.

Para a avaliação da proteólise e das propriedades viscoelásticas, foi utilizado um delineamento experimental do tipo split-plot, em que cada bloco foi dividido em parcelas (no caso, a adição ou não de CAD), e cada parcela foi divida em sub-parcelas (tempo de armazenamento refrigerado). O teste de F-ANOVA foi usado para verificar diferenças entre tratamentos, entre tempos e a interação tempo versus tratamento. Foi utilizado o teste de Tukey de comparações múltiplas para agrupar tratamentos e/ou tempos com médias cujas diferenças não foram estatisticamente significativas.

Os resultados obtidos a partir dos testes sensoriais foram analisados por meio da metodologia de análise de variância e do teste de Tukey.

\section{3 - RESULTADOS E DISCUSSÃO}

\section{1 - Composição química}

\subsection{1 - Composição do leite}

Na Tabela 1 são apresentados os valores de $\mathrm{pH}$, gordura, acidez titulável e densidade para o leite microfiltrado e padronizado a $0,4 \%$ de gordura.

TABELA 1 - Composição ${ }^{1}$ do leite microfiltrado padronizado utilizado na fabricação dos queijos prato light com e sem CAD

\begin{tabular}{lcc}
\hline & Queijo prato sem CAD & Queijo prato com CAD \\
\hline $\mathrm{pH}$ & $6,55^{\mathrm{a}}$ & $6,75^{\mathrm{a}}$ \\
Acidez ('Dornic) & $13^{\mathrm{a}}$ & $14^{\mathrm{a}}$ \\
Gordura $(\%)$ & $0,43^{\mathrm{a}}$ & $0,43^{\mathrm{a}}$ \\
Densidade $\left(\mathrm{g} / \mathrm{cm}^{3}\right)$ & $1,0278^{\mathrm{a}}$ & $1,0288^{\mathrm{a}}$ \\
\hline
\end{tabular}

${ }^{1}$ Os valores correspondem à média de duas repetições $(n=2)$. ${ }^{a, b}$ Médias com letras iguais na mesma linha, não diferem significativamente entre si $(p>0,05)$

\subsection{2 - Composição dos queijos}

A Tabela 2 apresenta a composição dos queijos prato light fabricados com e sem adição de CAD.

Os queijos não apresentaram diferenças significativas ( $p>0,05)$ em relação à composição química, indicando que a mesma não foi afetada pela adição de CAD. Esses resultados estão de acordo com os encontrados por KATSIARI, VOUTSINAS \& KONDYLI [17], RODRÍGUEZ et al. [22] e FENELON et al. [9], que apontaram que a composição de diferentes variedades de queijos light não foi afetada por diferentes tipos de culturas.

O teor de umidade encontrado (cerca de 50\%) foi bastante superior ao do queijo prato tradicional, cuja umidade média gira em torno de 42-44\% [12]. Este resultado está relacionado à redução do teor de gordura, que altera o balanço de componentes do queijo, provocando um aumento do conteúdo de umidade e uma conseqüente diminuição da relação sal/umidade (S/U). Essas modificações podem resultar em alterações nas características funcionais e sensoriais dos queijos [19].

TABELA 2 - Composição $^{1}$ dos queijos prato light fabricados com e sem adição de $\mathrm{CAD}^{2}$

\begin{tabular}{lcc}
\hline & \multicolumn{2}{c}{ Queijo prato } \\
Componente & Sem CAD (controle) & Com CAD \\
\hline Umidade (\%) & $52,47^{\mathrm{a}}$ & $55,26^{\mathrm{a}}$ \\
Gordura (\%) & $5,75^{\mathrm{a}}$ & $5,63^{\mathrm{a}}$ \\
Gordura em base seca (\%) & $12,1^{\mathrm{a}}$ & $11,85^{\mathrm{a}}$ \\
Proteína (\%) & $31,43^{\mathrm{a}}$ & $30^{\mathrm{a}}$ \\
Caseína (\%) & $30,03^{\mathrm{a}}$ & $28,47^{\mathrm{a}}$ \\
Sal (\%) & $1,96^{\mathrm{a}}$ & $1,98^{\mathrm{a}}$ \\
$\mathrm{S} / \mathrm{U}^{3}(\%)$ & $3,6^{\mathrm{a}}$ & $3,46^{\mathrm{a}}$ \\
Acidez titulável (\% ácido láctico) & $0,72^{\mathrm{a}}$ & $1,14^{\mathrm{a}}$ \\
pH & $5,36^{\mathrm{a}}$ & $5,11^{\mathrm{a}}$ \\
\hline${ }^{1}$ Os valores correspondem à média de duas repetições (n=2). ${ }^{2}$ Valores referentes à \\
composição dos queijos no $5^{\circ}$ dia após a fabricação. ${ }^{3} \mathrm{~S} / \mathrm{U}=$ Relação sal/umidade. ${ }^{\mathrm{a}, \mathrm{b}}$ Médias \\
com letras iguais, na mesma linha, não diferem significativamente entre si (p>0,05)
\end{tabular}

\section{2 - Proteólise}

A Figura 2 apresenta a evolução da extensão de proteólise durante os 45 dias de maturação para os queijos fabricados com e sem adição de CAD. Como mostra a Tabela 3, a adição de CAD não influenciou significativamente $(\mathrm{p}=0,0736)$ os índices de extensão de proteólise (\%NS (pH 4,6)/NT). Em relação ao tempo, houve um aumento significativo na extensão de proteólise $(\mathrm{p}=0,002)$ no decorrer dos 45 dias de maturação, tanto para o queijo controle como para o queijo com CAD (Tabela 3). A proteólise primária, que resulta na formação de compostos nitrogenados solúveis a pH 4,6, é atribuída principalmente à ação do coagulante residual, mas o sistema proteolítico das culturas lácticas também contribui, no decorrer do tempo, para a hidrólise da caseína e o conseqüente aumento da extensão de proteólise [23].

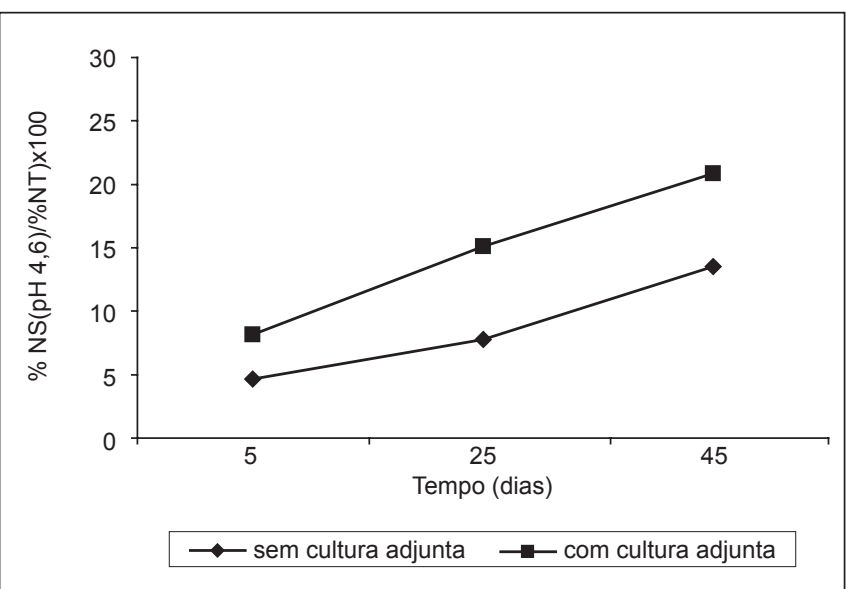

FIGURA 2 - Evolução dos índices de extensão de proteólise (\%NS ( $\mathrm{pH} 4,6) / \mathrm{NT}$ ) dos queijos prato light fabricados com e sem adição de $\mathrm{CAD}$ durante o tempo de maturação (45 dias). Os valores apresentados no gráfico correspondem à média de duas repetições $(n=2)$ 
TABELA 3 - ANOVA para os índices de extensão e profundidade de proteólise dos queijos prato light

\begin{tabular}{|c|c|c|c|c|c|}
\hline \multirow[b]{2}{*}{ Fatores } & \multirow[b]{2}{*}{$\mathrm{GL}^{1}$} & \multicolumn{2}{|c|}{ Extensão } & \multicolumn{2}{|c|}{ Profundidade } \\
\hline & & $\mathbf{Q M}^{1}$ & $\mathbf{p}^{1}$ & $\mathbf{Q M}^{1}$ & $\mathbf{p}^{1}$ \\
\hline Tratamentos $^{2}(\mathrm{~T})$ & 1 & 88,238 & 0,0736 & 10,9061 & 0,010 \\
\hline Erro (a) & 1 & 1,191 & & 0,0027 & \\
\hline Tempo $^{3}(\mathrm{t})$ & 2 & 96,689 & 0,002 & 21,4612 & 0,004 \\
\hline Interação $\left(T^{*} \mathrm{t}\right)$ & 2 & 3,707 & 0,051 & 2,9918 & 0,025 \\
\hline Erro (b) & 2 & 0,198 & & 0,0770 & \\
\hline
\end{tabular}

${ }^{\mathrm{I}} \mathrm{GL}=$ graus de liberdade; $\mathrm{QM}=$ quadrado médio; $\mathrm{P}=$ probabilidade. ${ }^{2}$ Foram utilizados dois tratamentos para a fabricação dos queijos: com adição de CAD e sem adição de CAD

${ }^{3} \mathrm{~A}$ proteólise foi avaliada nos dias 5, 25 e 45 após a fabricação

A Figura 3 apresenta a evolução da profundidade de proteólise durante os 45 dias de maturação para os queijos fabricados com e sem adição de CAD. A Tabela 3 mostra que a interação entre o tipo de tratamento e o tempo foi significativa $(\mathrm{p}=0,025)$, indicando que o queijo controle e o queijo com CAD se comportam de maneira diferente ao longo do tempo, em relação aos índices de profundidade de proteólise (\%NS (TCA 12\%)/NT). No final do tempo de maturação (45 dias), os queijos fabricados com CAD apresentaram índice de profundidade de proteólise significativamente maior $(\mathrm{p}<0,05)$ que o dos queijos controle. O aumento dos índices de profundidade de proteólise ao longo do tempo pode ser explicado pela atuação das bactérias do fermento láctico mesófilo, que possuem um sistema de proteinases e peptidases capaz de hidrolisar os oligopeptídeos resultantes da proteólise primária [10]. Nos queijos fabricados com CAD, a atividade do sistema proteolítico da cultura adjunta utilizada (Lactobacillus helveticus) provavelmente contribuiu para uma proteólise secundária mais pronunciada do que a dos queijos controle [8].

Em geral, a diferença entre os índices de proteólise dos queijos com e sem adição de CAD foi mais acentuada após 25 dias de maturação (Figura 3). Isso mostra que pode ser necessário um tempo maior de cura para que a CAD tenha um efeito mais expressivo.

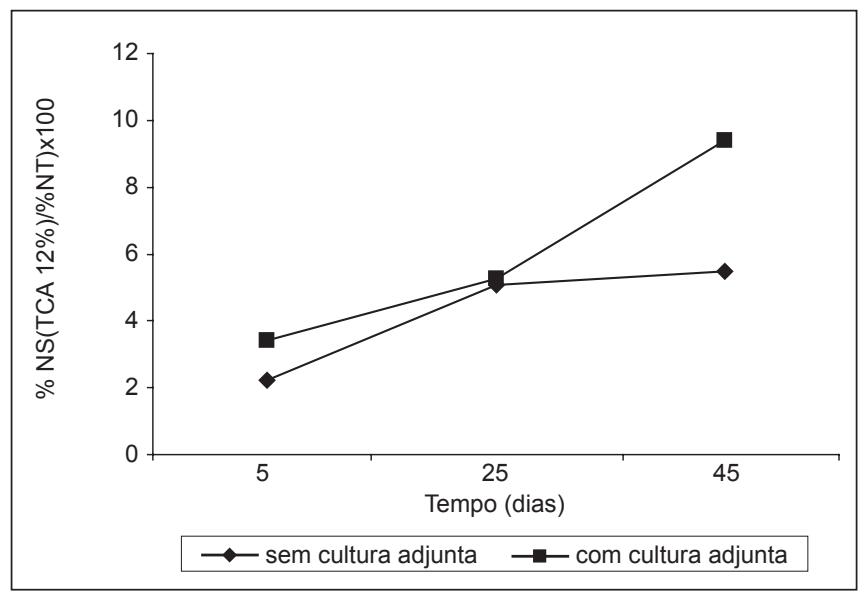

FIGURA 3 - Evolução dos índices de profundidade de proteólise (\%NS (TCA 12\%)/NT) dos queijos prato light fabricados com e sem adição de CAD durante o tempo de maturação (45 dias). Os valores apresentados no gráfico correspondem à média de duas repetições $(n=2)$

\section{3 - Testes reológicos}

O modelo generalizado de Maxwell com $n=2$ apresentou boa correlação com as curvas obtidas experimentalmente $\left(R^{2}>0,99\right)$. A Figura 4 mostra as curvas de relaxação obtidas para os queijos com e sem CAD, após 25 dias de maturação.

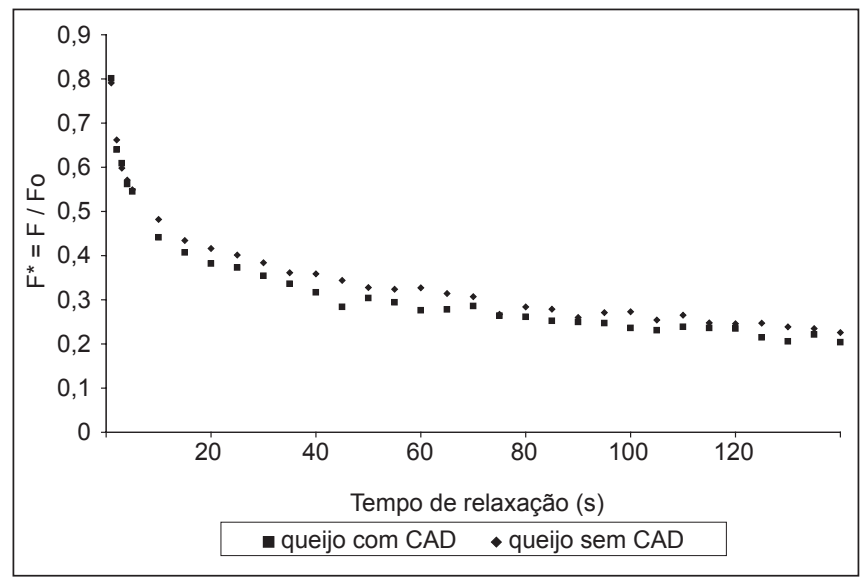

FIGURA 4 - Curvas de relaxação obtidas para os queijos prato light fabricados com e sem adição de CAD. As curvas são referentes à primeira repetição e a um tempo de maturação igual a 25 dias

As Tabelas 4 e 5 mostram que a adição de CAD não influenciou significativamente $(\mathrm{p}>0,05)$ os parâmetros viscoelásticos dos queijos. A variação desses parâmetros no decorrer do tempo também não foi significativa ( $p>0,05)$. Entretanto, o valor $\mathrm{p}$ para a variação do parâmetro $\mathrm{E}_{0}$ com o tempo foi muito pequeno $(\mathrm{p}=0,088)$. Como pode ser observado na Figura 5, houve uma tendência de diminuição no módulo elástico de equilíbrio $\left(\mathrm{E}_{0}\right)$ com o tempo de maturação. Pequenas diferenças nas características dos queijos são difíceis de detectar com um pequeno número de experimentos, de modo que mais repetições seriam necessárias para confirmar a tendência observada. A diminuição do módulo elástico de equilíbrio ao longo do tempo indica uma redução na elasticidade do queijo, sugerindo que houve um enfraquecimento das ligações protéicas da matriz de caseína devido à proteólise primária [11]. De fato, os valores obtidos para os índices de extensão de proteólise, que são indicativos da proteólise primária, aumentaram significativamente com o tempo de maturação (Tabela 3).

TABELA 4 - ANOVA para os módulos de elasticidade $\mathrm{E}_{0}, \mathrm{E}_{1} \mathrm{e}_{2}$ dos queijos prato light $^{1}$

\begin{tabular}{|c|c|c|c|c|c|c|c|}
\hline \multirow[b]{2}{*}{ Fatores } & \multirow[b]{2}{*}{$\mathrm{GL}^{2}$} & \multicolumn{2}{|c|}{$\mathbf{E}_{0}$} & \multicolumn{2}{|c|}{$E_{1}$} & \multicolumn{2}{|c|}{$E_{2}$} \\
\hline & & $\mathbf{Q M}^{2}$ & $\mathbf{p}^{2}$ & $\mathbf{Q M}^{2}$ & $\mathbf{p}^{2}$ & $\mathbf{Q M}^{2}$ & $p^{2}$ \\
\hline Tratamentos $^{3}(\mathrm{~T})$ & 1 & 26511 & 0,338 & 451907 & 0,3152 & 1546 & 0,652 \\
\hline Erro(a) & 1 & 9120 & & 131749 & & 4187 & \\
\hline Tempo $^{4}(\mathrm{t})$ & 2 & 65070 & 0,088 & 31314 & 0,928 & 14099 & 0,567 \\
\hline Interação ( $\left.T^{*} t\right)$ & 2 & 1258 & 0,914 & 212993 & 0,632 & 17795 & 0,500 \\
\hline Erro(b) & 4 & 13682 & & 412655 & & 21510 & \\
\hline
\end{tabular}

${ }^{1}$ Os módulos de elasticidade $\mathrm{E}_{0}, \mathrm{E}_{1}$ e $\mathrm{E}_{2}$ foram obtidos a partir de testes de relaxação. $\mathrm{E}_{0}$ é o módulo de elasticidade de equilíbrio, e $\mathrm{E}_{1}$ e $\mathrm{E}_{2}$ correspondem, respectivamente, aos módulos de elasticidade dos elementos do modelo com menor e maior tempo de relaxação. ${ }^{2} \mathrm{GL}=$ graus de liberdade; $\mathrm{QM}=$ quadrado médio; $\mathrm{P}=$ probabilidade

${ }^{3}$ Foram utilizados dois tratamentos para a fabricação dos queijos: com adição de CAD

e sem adição de CAD. ${ }^{4}$ As propriedades reológicas foram avaliadas nos dias 5,25 e 45 após a fabricação 
TABELA 5 - ANOVA para as viscosidades $\eta_{1}$ e $\eta_{2}$ dos queijos prato light ${ }^{1}$

\begin{tabular}{lcccccc}
\hline & & \multicolumn{2}{c}{$\eta_{1}$} & & \multicolumn{2}{c}{$\eta_{2}$} \\
\cline { 3 - 4 } \cline { 6 - 7 } Fatores & $\mathbf{G L}^{2}$ & $\mathbf{Q M}^{2}$ & $\mathbf{P}^{2}$ & & $\mathbf{Q M}^{2}$ & $\mathbf{p}^{2}$ \\
\hline Tratamentos $^{3}(\mathrm{~T})$ & 1 & 538362 & 0,604 & & 214734242 & 0,171 \\
Erro(a) & 1 & 1045493 & & & 16237357 & \\
Tempo $^{4}(\mathrm{t})$ & 2 & 60401 & 0,935 & & 251238080 & 0,163 \\
Interação $\left(\mathrm{T}^{*} \mathrm{t}\right)$ & 2 & 1389895 & 0,314 & & 260576 & 0,997 \\
Erro(b) & 4 & 884364 & & & 85055573 & \\
\hline
\end{tabular}

${ }^{1}$ As viscosidades $\eta_{1}$ e $\eta_{2}$ foram obtidas a partir de testes de relaxação e correspondem, respectivamente, aos elementos do modelo com menor e maior tempo de relaxação. ${ }^{2} \mathrm{GL}=$ graus de liberdade; $\mathrm{QM}=$ quadrado médio; $\mathrm{P}=$ probabilidade. ${ }^{3}$ Foram utilizados dois tratamentos para a fabricação dos queijos: com adição de CAD e sem adição de CAD. ${ }^{4} \mathrm{As}$ propriedades reológicas foram avaliadas nos dias 5, 25 e 45 após a fabricação

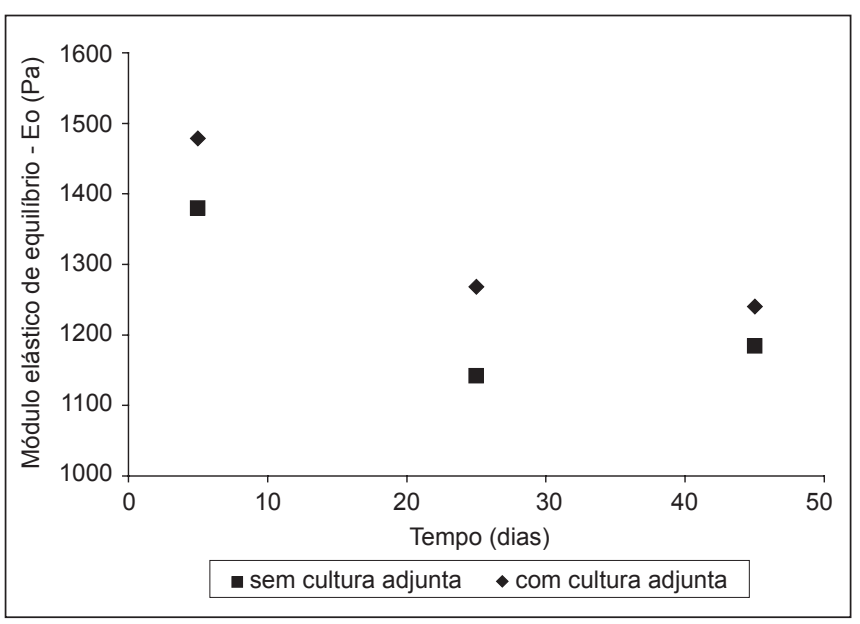

FIGURA 5 - Módulo elástico de equilíbrio $\left(\mathrm{E}_{0}\right)$ dos queijos prato light fabricados com e sem adição de CAD em função do tempo de maturação (45 dias). Os valores apresentados no gráfico correspondem à média de duas repetições $(n=2)$

\section{4 - Análise sensorial}

A Tabela 6 apresenta as notas médias atribuídas aos queijos pelos provadores, para os atributos aparência, aroma, sabor, textura e impressão global. Houve diferença significativa $(\mathrm{p}<0,05)$ na aceitação dos queijos com e sem adição de CAD para os atributos aroma, textura e impressão global, sendo que os queijos fabricados com CAD apresentaram notas médias mais altas em relação a esses atributos.

A melhoria da textura, observada nos queijos fabricados com o uso de Lactobacillus helveticus como cultura adjunta, deveu-se provavelmente à ação adicional do sistema proteolítico dessa bactéria sobre a matriz de caseína. Os resultados obtidos para os índices de extensão e profundidade de proteólise (Figuras 2 e 3) reforçam esse argumento: os valores foram maiores para o queijo fabricado com CAD, especialmente após 25 dias de maturação. A proteólise primária da caseína, promovida pelo coagulante, é a principal responsável pelo amolecimento inicial da textura do queijo, mas enzimas provenientes de microorganismos também contribuem para a hidrólise e o enfraquecimento da rede protéica [11].
Convém observar que, embora a diferença entre a textura dos queijos com e sem adição de CAD tenha sido sensorialmente significativa, ela não foi detectada nos testes reológicos (Tabelas 4 e 5). Isso pode ser explicado pelo fato de que a avaliação sensorial de textura envolve a interação entre o alimento e os tecidos da boca, que também sofrem deformação. Nas medidas instrumentais, por outro lado, apenas o alimento é deformado, o que resulta em respostas diferentes das obtidas sensorialmente. Assim, embora as análises reológicas gerem dados relacionados à textura, a correlação entre esses dados e a percepção da textura por consumidores não treinados é limitada [13].

No que diz respeito ao aroma, a maior aceitação dos queijos com CAD deveu-se, essencialmente, ao aumento da atividade proteolítica resultante da adição do Lactobacillus helveticus como cultura adjunta. As aminopeptidases associadas a culturas adjuntas, em especial o Lactobacillus helveticus, são responsáveis pela redução do sabor amargo e pelo aumento da concentração de peptídeos de sabor desejável e precursores de sabor e aroma [6, 7, 8]. Entretanto, embora a cultura adjunta tenha provocado melhorias no aroma, os provadores não perceberam diferenças no sabor dos queijos aos 40 dias de maturação.

A diversidade da microflora tem sido apontada como o principal fator determinante do perfil de aroma e sabor dos queijos [18]. É importante ressaltar que os queijos foram fabricados a partir de leite microfiltrado, e, portanto, praticamente isento de microorganismos, já que a microfiltração resulta em valores de retenção de bactérias e esporos da ordem de 99,1 a 99,9\% [20]. Assim sendo, o sabor e o aroma dos queijos podem ser considerados resultantes principalmente da ação da cultura láctica e da cultura adjunta, já que a competição de outros microorganismos foi minimizada pelo uso de leite microfiltrado.

TABELA 6 - Notas médias $(\mathrm{n}=30)$ atribuídas pelos provadores aos queijos prato light fabricados com e sem adição de CAD1

\begin{tabular}{lcc}
\hline & \multicolumn{2}{c}{ Queijo prato } \\
Atributo & Sem CAD (controle) & Com CAD \\
\hline Aparência & $7,30^{\mathrm{a}}$ & $7,23^{\mathrm{a}}$ \\
Aroma & $6,93^{\mathrm{b}}$ & $7,33^{\mathrm{a}}$ \\
Sabor & $6,57^{\mathrm{a}}$ & $6,63^{\mathrm{a}}$ \\
Textura & $6,27^{\mathrm{b}}$ & $7,30^{\mathrm{a}}$ \\
Impressão global & $6,73^{\mathrm{b}}$ & $7,27^{\mathrm{a}}$ \\
\hline${ }^{1}$ A avaliação sensorial foi realizada no $40^{\mathrm{o}}$ dia após a fabricação. a,bMédias com letras
\end{tabular}
iguais, na mesma linha, não diferem significativamente entre si $(p>0,05)$

A Figura 6 mostra o histograma de freqüências para o atributo intenção de compra. Os resultados refletem as diferenças encontradas em relação aos atributos textura, aroma e impressão global. Cerca de 70\% dos provadores, certamente ou provavelmente, comprariam o queijo prato light fabricado com adição de CAD, o que indica uma boa aceitação sensorial. Já no caso do queijo controle, a maior parte dos provadores $(56,7 \%)$ tinha dúvidas ou provavelmente não compraria o produto, indicando um menor nível de aceitação. 


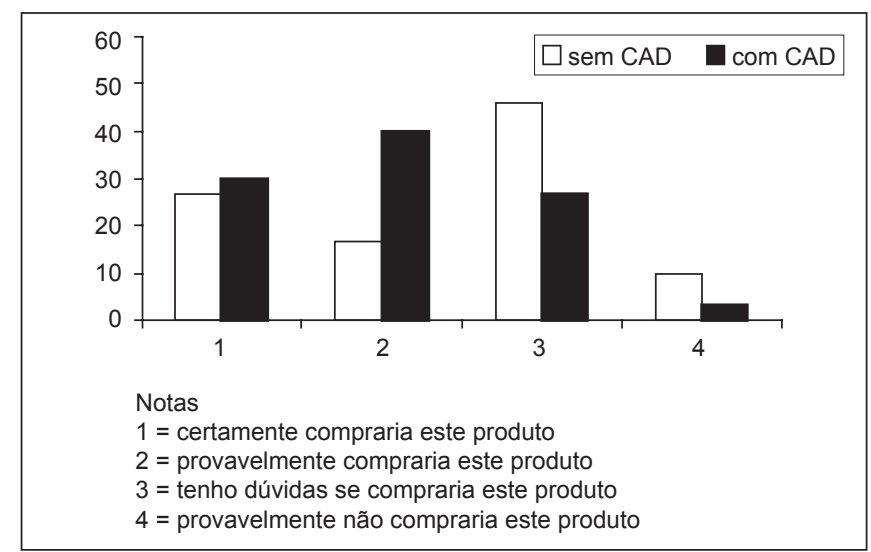

FIGURA 6 - Histograma de intenção de compra dos queijos prato light fabricados com e sem $\mathrm{CAD}$

É importante ressaltar que as diferenças entre o queijo controle e o queijo com CAD foram relativamente pequenas, mesmo quando estatisticamente significativas. Apesar disso, os testes de consumidor demonstraram que o uso da cultura adjunta aumentou a intenção de compra dos queijos. Assim, pode-se dizer que o Lactobacillus helveticus apresenta um bom potencial para melhorar os atributos sensoriais do queijo prato light, porém mais estudos são necessários. Uma possibilidade de acentuar as melhorias provocadas pelo uso de CAD seria, por exemplo, aumentar o tempo de cura dos queijos: os índices de proteólise mostraram que o efeito da CAD foi maior ao final do tempo de maturação, o que sugere que pode ser necessário um tempo maior de cura para que a melhoria no sabor dos queijos se torne mais evidente.

\section{4 - CONCLUSÕES}

O uso de cultura adjunta influenciou a profundidade de proteólise, que foi maior no final do tempo de maturação para o queijo produzido com CAD. A avaliação dos parâmetros viscoelásticos não apontou diferenças significativas entre os queijos com e sem CAD. Entretanto, a avaliação sensorial mostrou que o queijo produzido com cultura adjunta foi mais aceito em relação à textura. O uso de cultura adjunta também aumentou a intenção de compra e a aceitação dos queijos para os atributos aroma e impressão global. O estudo mostrou que o uso do Lactobacillus helveticus como cultura adjunta apresenta bom potencial no sentido de melhorar a textura, o aroma e, principalmente, a aceitação sensorial do queijo tipo prato light.

\section{5 - REFERÊNCIAS BIBLIOGRÁFICAS}

[1] ARDÖ, Y. Flavour and texture in low fat cheese. In: LAW, B.A. (ed.). Microbiology and biochemistry of cheese and fermented milk, $2^{\text {a }}$ ed. London: Blackie Academic \& Professional, cap. 6, p. 2072181997.

[2] ARDO, Y.; LARSSON, P.O.; LINDMARK-MANSSON, H.; HEDENBERG, A. Studies of peptidolysis during early maturation and its influence on low fat cheese quality. Milchwissenschaft, v. 44, p. 485-489, 1989.

[3] ASSOCIATION OF OFFICIAL ANALYTICAL CHEMISTS. Official Methods of Analysis of AOAC International, $17^{\text {a }}$ edição, Gaithersburg, 1997.

[4] BERTOLA, N.C.; BEVILACQUA, A.E.; ZARITZKY, N.E. Changes in rheological and viscoelastic properties and protein breakdown during the ripening of 'Port Salut Argentino' cheese. Int. J. of Food Sci. and Technol., v. 26, p. 467-478, 1991.

[5] BYNUM, D.G., BARBANO, D.M. Whole milk reverse osmosis retentates for Cheddar cheese manufacture: chemical changes during ageing. J. Dairy Sci., v. 68, p. 1-10, 1985.

[6] DRAKE, M.A.; SWANSON, B.G. Reduced and low-fat cheese technology: a review. Trends in Food Sci. and Technol., v. 6, p. 366-369, 1995.

[7] DRAKE, M.A.; BOYLSTON, T.D.; SPENCE, K.D.; SWANSON, B.G. Chemical and sensory effects of a Lactobacillus adjunct in cheddar cheese. Food Res. Int., v. 29, n. 3-4, p. 381-387, 1996.

[8] EL SODA, M.; MADKOR, S.A.; TONG, P.S. Adjunct cultures: recent developments and potencial significance to the cheese industry. J. Dairy Sci., v. 83, p. 609-619, 2000.

[9] FENELON, M.A.; RYAN, M.P.; REA, M.C.; GUINEE, T.P.; ROSS, R.P.; HILL, C.; HARRINGTON, D. Elevated temperature ripening of reduced-fat cheddar made with or without lacticin 3147 - producing starter culture. J. Dairy Sci., v. 82, p. 10-22, 1999.

[10] FOX, P.F.; SINGH, T.K.; McSWEENEY, P.L.H. Biogenesis of flavor compounds in cheese. In: MALIN, E.L.; TUNICK, M.H. (eds.). Chemistry of structure - Function Relationships in cheese. New York, London: Plenum Press, 1995. cap.6, p. 59-98.

[11] FOX, P.F.; GUINEE, T.P.; COGAN, T.M.; McSWEENEY, P.L.H. Fundamentals of Cheese Science. Gaithersburg, Aspen, 2000. $587 \mathrm{p}$.

[12] FURTADO, M.M.; LOURENÇO-NETO, J.P.M. Tecnologia de Queijos. Manual Técnico para a Produção Industrial de Queijos. São Paulo, Dipemar, 1994. cap. 15, Minas Frescal, p. 73-75.

[13] GUNASEKARAN, S.; AK, M.M. Cheese texture. In: GUNASEKARAN, S.; AK, M.M. Cheese Rheology and Texture. Boca Raton, London, New York, Washington, CRC Press, 2003. cap. 7.

[14] HINRICHS, J. Incorporation of whey proteins in cheese. Int. Dairy J., v. 11, p. 495-503, 2001.

[15] INSTITUTO ADOLFO LUTZ. Normas Analíticas do Instituto Adolfo Lutz: Métodos Químicos e Físicos para Análise de Alimentos, $3^{\mathrm{a}}$ ed., v. 1, São Paulo, 1985.

[16] JOHNSON, J.; ETZEL, M. Properties of Lactobacillus helveticus CNRZ-32 attenuated by spray drying, freeze-drying or freezing. J. Dairy Sci., v. 78, p. 761768, 1995.

[17] KATSIARI, M.C.; VOUTSINAS, L.P.; KONDYLI, E. Improvement of sensory quality of kefalograviera-type cheese by using commercial special starter cultures. J. Dairy Sci., v. 85, n. 11, p. 2.759-2.767, 2002.

[18] LAW, B.A. Controlled and accelerated cheese ripening: the research base for new technologies. Int. Dairy J., 
v. 11, p. 383-398, 2001.

[19] MISTRY, V.V. Low fat cheese technology. Int. Dairy J., v 11, p. 413-422, 2001.

[20] PEDERSEN, P.J. Microfiltration for the reduction of bacteria in milk and brine. In: INTERNATIONAL DAIRY FEDERATION. New Applications of Membrane Processes. Brussels, International Dairy Federation, 1992. Special Issue, n. 9.201, cap. 4, p. 33-50.

[21] RICHARDSON, G.H. Standard Methods for Examination of Dairy Products. Washington, American Publ. Health Assoc., 1985.

[22] RODRÍGUEZ, J.; REQUENA, T.; GOUDEDRANCHE, H.
MAUBOIS, J. L.; JUAREZ, M. Accelerated ripening of reduced fat semi-hard cheese from a mixture of cow's, goat's and ewe's ultrafiltrated milk by using a Lac-Prt ${ }^{-}$ strain of lactococci. Lait, v. 76, p. 513-522, 1996.

[23] RODRÍGUEZ, J. Recent advances in the development of low-fat cheeses. Trends in Food Sci. and Technol., v. 9, p. 249-254, 1998.

[24] STEELE, J.L. Contribution of lactic acid bacteria to cheese ripening. In: MALIN, E.L.; TUNICK, M.H. (eds.) Chemistry of Structure - Function Relationships in Cheese. New York, London, Plenum Press, 1995. cap. 12, p. 209-220. 